\title{
The Effect of Glycine max Extract Diets on Changes in NR2B Gene Expression, Cognitive Vitality and Neurotoxicity in High Concentrate Consumption
}

\author{
M.N. Shahib, ${ }^{1} \quad$ M.R.A.A. Syamsunarno, ${ }^{1} \quad$ A. Faried ${ }^{1}$ \\ D. Yuliana, ${ }^{1} \quad$ D. Anggraeni, ${ }^{1} \quad$ L. Yuniarti ${ }^{2}$ \\ and F. Tih ${ }^{3}$
}

\begin{abstract}
The effects of soybean extract (Glycine max) on NR2B expression, cognitive vitality and neurotoxicity have not been exclusively reported. Here, we examined the correlation between Glycine max concentration and the N-methyl-D-aspartate (NMDA) receptor NR2B. We observed the brain weight, bodyweight and body movement in animals that recieved soybean extract in their food. Brain tissues from five groups of rats treated with five different concentrations of soybean extract (5-50\% of total diet calories) were collected. Rats without treatment served as the control group. NR2B expression was determined using RT-PCR. Average values of escape latency (EL) on day four in the control, $5 \%, 10 \%$ and $20 \%$ groups were $34.5,29.67,27.2$ and 33.83 seconds, respectively. The EL of the $10 \%$ group was significantly shorter than that of the control. The low (5-10\%) and moderate (20\%) extract concentrations were not found to induce any abnormality in body movements, whereas the high concentration (40$50 \%$ ) groups were found to have some movement disorders after four weeks of administration. The cerebellum weight of the high concentration group (50\%) was decreased $18 \%$ from the pre-treatment weight, and this decrease might be related to the movement abnormality, which was possibly due to a defect of the CNS in this group. Specifically, we speculated that this abnormality might be due to damage in the cerebellum. These events might be initiated by an increase of NR2B as an adaptive process in the low and high soybean extract groups (5-40\%), followed by a sudden decrease in NR2B in the $50 \%$ group due to the possibility of brain injury. The low percentage Glycine max extract diet $(<$ $5 \%$ ) is recommended, and $5-10 \%$ can be tolerated, but more than $20 \%$ is not recommended. High concentrations $(40-50 \%)$ of soybean extract were found to have neurotoxicilogical effects. (Kitakanto Med J $2010 ; 60: 41 \sim 47)$
\end{abstract}

Key Words : Glycine max extract diet, NR2B gene expression, Spatial memory, Neurotoxicity

\section{Introduction}

Soybean and soy products have been used in traditional food for hundreds of years in many Asian countries, including Indonesia. The products have been used in tofu, tempeh, burgers, baby formulas and osteophoretic diets. The Asian diet is characterized by a high content of soy and soy products. ${ }^{1}$ Soy products are widely known as a healthy source of protein, and a diet high in soy protein is commonly known as a healthy, natural diet. Because of these properties, its high use, and the different chemicals this legume contains, soybean makes an excellent source of high-quality protein; it has low saturated fat content, high unsaturated fatty acid content, and significant amounts of dietary fiber, lecithin and isoflavones. ${ }^{2}$ Lecithin is needed for neurogenesis, ${ }^{3}$ whereas isoflavone (phytoestrogen) plays a role in cognitive function. ${ }^{4}$

Most of the previous studies have focused on 
soybean supplementation as an alternative method of growth maintenance and health development, as well as a preventative measure against chronic diseases. ${ }^{5-7}$ In contrast to the generally accepted idea that soy is a healthy food, recent evidence reveals that soy consumption has been linked to numerous disorders, including thiamine deficiency in infants, ${ }^{8}$ infertility, ${ }^{9}$ a reduction in body weight, ${ }^{10}$ and effects in brain and reproductive development. ${ }^{11}$ There are considerable controversies with regard to the soybean and soy products. The critical information concerning side effects of soybean or soy product on brain tissue, brain weight loss and body weight loss will be needed. The N-methyl-Daspartate (NMDA) receptor is a heteromeric ligand gated ion channel that interacts with multiple proteins. $^{12}$ Neurotransmission involving NMDA receptors has been involved in a variety of unique roles, one of which is its participation in glutamate neurotoxicity. ${ }^{13}$ NMDA receptors are composed of seven subunits; one of them is NR2B. Recently, Liu Y et al. ${ }^{14}$ reported that activation of $\mathrm{NR} 2 \mathrm{~B}$-containing NMDA receptors results in excitotoxicity and increased neuronal apoptosis. The avoidance of these phenomena is very important to promote neuroprotection and to improve NMDA receptor activities. The NR2B subunit has also been implicated in modulating feeding behavior ${ }^{15}$ and has been shown to be involved in a number of human disorders.

In the present study, the effect of low and high concentrations of dietary soybean extract (Glycine max) on NR2B gene expression in the rat brain and its effects on cognitive vitality were investigated. Additionally, the cerebrum, cerebellum and total brain weights and bodyweights were also determined.

\section{Materials and Methods}

Extraction and dose concentration of Glycine max extract. The soybeans (Glycine max) were ground into powder and extracted with pure water $(2$ gram $/ \mathrm{cc}$ ). The dose for each treated group (5\% to $50 \%$ ) was calculated based on the conversion formula of human intake. The estimate for the daily soybean dose for rats was based on the daily soybean consumption of humans and was calculated as shown in Supplemental Table 1.

Animal studies. Specific pathogen-free, adult, male Wistar rats were obtained from Biofarma (Bandung, Indonesia) according to the standards of the National Animal Care Committee, Bandung, Indonesia. All rats were housed under conditions that included laminar airflow. They were maintained on standard laboratory feed and under 12-hour light/dark cycles. This study was approved by the Animal Research Ethics Board of Universitas Padjadjaran. One week
Supplement Table 1 Soybean dose concentration from total calorie

\begin{tabular}{cccc}
\hline \multirow{2}{*}{ Group } & \multirow{2}{*}{$\begin{array}{c}\text { Soybean intake in } \% \\
\text { (total calorie/day) }\end{array}$} & \multicolumn{2}{c}{ Soybean (in gram) } \\
\cline { 3 - 4 } & $0 \%$ & 0 & 0 \\
I & $5 \%$ & 276 & 4.97 \\
II & $10 \%$ & 553 & 9.95 \\
III & $20 \%$ & 1105 & 19.9 \\
IV & $40 \%$ & 2211 & 39.8 \\
V & $50 \%$ & 2777 & 49.9 \\
VI & $50 u{ }^{*}$ & \\
\hline
\end{tabular}

* : value from human to mouse times 0.018

after arrival and environmental adaptation, the rats $(n=36)$, weighing 150-200 grams, were divided into six groups (each group $n=6$ ). The control group was fed a standard rat chow. Treated groups were fed a standard chow plus different concentrations of soybean extract through an oral gastric tube (2 times a day for 28 days). The concentrations of soybean were 5\%, $10 \%, 20 \%, 40 \%$ and $50 \%$ of total daily energy in the treated groups, respectively. After four weeks of soybean extract consumption, the rat brains were removed and weighed. Part of the brain was stored in RNA later for RNA isolation, and the other part of the brain was fixed in $10 \%$ formalin and embedded in paraffin ; then, $4 \mu \mathrm{m}$ sections were processed with hematoxylin and eosin (H\&E) staining.

RNA Extraction. Brain tissues were minced thoroughly and homogenized in $4 \mathrm{M}$ guanidine throcyanate containing $0.1 \%$ Tris $-\mathrm{Cl}$ and $0.97 \% \beta^{-}$ mercaptoethanol (Promega). The homogenized solution was centrifuged at $14.000 \times \mathrm{g}$. RNA pellets were recovered and purified by phenol-chloroform extraction and ethanol precipitation. The purity and concentration were measured using the NanoDrop ${ }^{\circledR}$ ND1000 UV-Vis Spectrophotometer (Thermo Fisher).

RT-PCR. RT-PCR was performed using the onestep RT-PCR system (Promega) using cDNA primers for the $N R 2 B$ gene (forward: GGTAGCCATGAACGAGACTG and reverse: TTCACGAAGTCCTGGTAGCC) and for the GAPDH gene (forward: TCGGTGTGAACGGATTTGGC and reverse : GCTTCCCGTTGATGACAAGC), which served as a control. RT-PCR reaction mixtures were subjected to reverse transcription for $45 \mathrm{~min}$ at $45^{\circ} \mathrm{C}$, followed by inactivation of the $\mathrm{RT}$ enzyme at $94^{\circ} \mathrm{C}(2 \mathrm{~min})$ and by $40 \mathrm{PCR}$ cycles at $94^{\circ} \mathrm{C}(30 \mathrm{sec}), 60^{\circ} \mathrm{C}(1 \mathrm{~min})$, and $68^{\circ} \mathrm{C}$ $(2 \mathrm{~min})$ with a final extension at $68^{\circ} \mathrm{C}(10 \mathrm{~min})$. The products were then run in $3 \%$ agarose gel. Densitometry was performed by using Adobe Photoshop (Apple, Inc., Cupertino, CA), and acquisition and analysis were performed by the Quantity One program (BioRad).

Morris Water Maze Test (MWMT). This experi- 
Table 1 Effects of Glycine-max after four weeks consumption on change of brain weight

\begin{tabular}{|c|c|c|c|c|}
\hline & Cereb $(\mathrm{gr}) \pm \mathrm{SD}$ & Cerebel $(\mathrm{gr}) \pm \mathrm{SD}$ & Brain $(\mathrm{gr}) \pm \mathrm{SD}$ & Mortality \\
\hline Control & $1.294 \pm 0.04$ & $0.41 \pm 0.04$ & $1.704 \pm 0.06$ & none \\
\hline $5 \%$ Glycine $\max$ & $1.29 \pm 0.06$ & $0.414 \pm 0.02$ & $1.704 \pm 0.07$ & none \\
\hline $10 \%$ Glycine $\max$ & $1.28 \pm 0.05$ & $0.422 \pm 0.03$ & $1.702 \pm 0.04$ & none \\
\hline $20 \%$ Glycine $\max$ & $1.276 \pm 0.06$ & $0.425 \pm 0.06$ & $1.701 \pm 0.07$ & none \\
\hline $40 \%$ Glycine $\max$ & $1.275 \pm 0.06$ & $0.428 \pm 0.03$ & $1.703 \pm 0.08$ & $40 \%$ \\
\hline $50 \%$ Glycine $\max$ & $\begin{array}{r}1.4 \pm 0.05 \\
(\operatorname{up} 8.2 \%)^{*}\end{array}$ & $\begin{array}{c}0.335 \pm 0.05 \\
(\text { down } 18 \%)^{*}\end{array}$ & $\begin{array}{l}1.735 \pm 0.08 \\
(\text { up } 1.82 \%)^{*}\end{array}$ & $50 \%$ \\
\hline
\end{tabular}

Cereb : Cerebrum, Cerebel : Cerebellum, gr : gram, SD : Standard Deviation, * : compared to each control group

ment was first described by Morris in $1984 .{ }^{16}$ Spatial memory was identified by measuring the escape latency (EL). We divided our rats into four groups (control, 5\%, 10\% and 20\%). Glycine max was administered for 30 days, and EL was measured for four days, as described previously. ${ }^{16}$ The faster the EL times, the better the spatial memory.

Statistical Analysis. Statistical analysis was performed using the Stat View software (ver.5.0, SAS Institute Inc., NC). The statistical significance of the differences was considered significant when the $p^{-}$ value was $<0.05$.

\section{Results}

We examined the effects of Glycine max extract diets at the molecular level. We isolated RNA from rat brains and then subjected it to RT-PCR to observe expression of the NR2B gene. NR2B (341 bp ; Figure 1A) was observed only slightly in control brain, and its expression gradually increased in the four treated groups $(5 \%, 10 \%, 20 \%$, and $40 \%)$, but was only expressed at a low level in the $50 \%$ group. After normalization with GADPH, as shown in Figure 1B, the expression of the NR2B gene in the control group was very weak $(0.008$; Figure $1 \mathrm{C})$. The expressions of the NR2B gene in rat brain tissues of the $5 \%, 10 \%$, $20 \%, 40 \%$ and $50 \%$ groups were $0.55,0.78,0.91,1.00$ and 0.03 (Figure 1C), respectively. The results showed that NR2B gene expression was gradually increased as the dietary soybean concentration was increased, beginning with the control group up to the $40 \%$ treated group (Figure $1 \mathrm{~A}$ and C). Surprisingly, the NR2B expression of the $50 \%$ group was decreased 33.3 -fold from the $40 \%$ group. In the $50 \%$ group, the NR2B expression was weaker than it was in the other treated groups, and this decrease might cause the neurotoxicological effect that leads to cell death.

MWMT was performed to observe the EL in rats with and without treatment. There were no statistically significant differences in EL in each group from day one until day-three (data not shown). On day four, the EL means in the control, 5\%, 10\% and 20\% groups were $34.5,29.67,27.2$ and 33.83 seconds (sec),
Table 2 Effects of Glycine max after 4weeks consumption on physical performance

\begin{tabular}{rcc}
\hline & $\begin{array}{c}\text { Limply and body } \\
\text { movement disorder }\end{array}$ & $\begin{array}{c}\text { Neurological } \\
\text { defisit }\end{array}$ \\
\hline Control & none & none \\
$5 \%$ Glycine max & none & none \\
$10 \%$ Glycine $\max$ & none & none \\
$20 \%$ Glycine $\max$ & none & none \\
$40 \%$ Glycine $\max$ & yes & yes \\
$50 \%$ Glycine $\max$ & yes & yes \\
\hline
\end{tabular}

respectively. We observed a shortened EL by $4.83 \mathrm{sec}$ (up to $14 \%$ ), $7.3 \mathrm{sec}$ (up to $21.6 \%$ ), and $0.67 \mathrm{sec}$ (up to $1.94 \%$ ) in $5 \%, 10 \%$ and $20 \%$ groups, respectively, compared with that of the control group. There was a significant improvement in EL in treated rats, $p=$ 0.044. Among the treated groups, as shown in Figure 2 , using univariate analysis, the $10 \%$ group showed a significant improvement compared with the control group $(p=0.01)$. Meanwhile, the $5 \%$ and $20 \%$ groups did not show any improvement $(\mathrm{p}=0.053$ and $\mathrm{p}=$ 0.810 , respectively).

Further, there was no bodyweight difference between the control group and the treated groups ( $p>$ 0.05). The brain-weight measurements in rats fed with Glycine max extract diets for four weeks showed that the total brain weight (cerebrum plus cerebellum) was quite similar to that of the control group $(\mathrm{p}>$ $0.05)$. In the $50 \%$ diet group, the cerebrum and cerebellum weights were increased $8.2 \%(p=0.013)$ and decreased 18\% $(p=0.028)$, respectively (Table 1). Moreover, we observed an abnormality of body movement in rats fed the $40 \%$ and $50 \%$ diets (Table 2). It is tempting to speculate that there was a possibility of neurotoxic effects in rats fed with the high concentration of Glycine max extract diets (40\% and 50\%). The increased cerebrum weight and decreased cerebellum weight might have a serious effect on the body's function, especially in the case of the cerebellum, which is highly associated with the coordination of movement, posture and balance. 


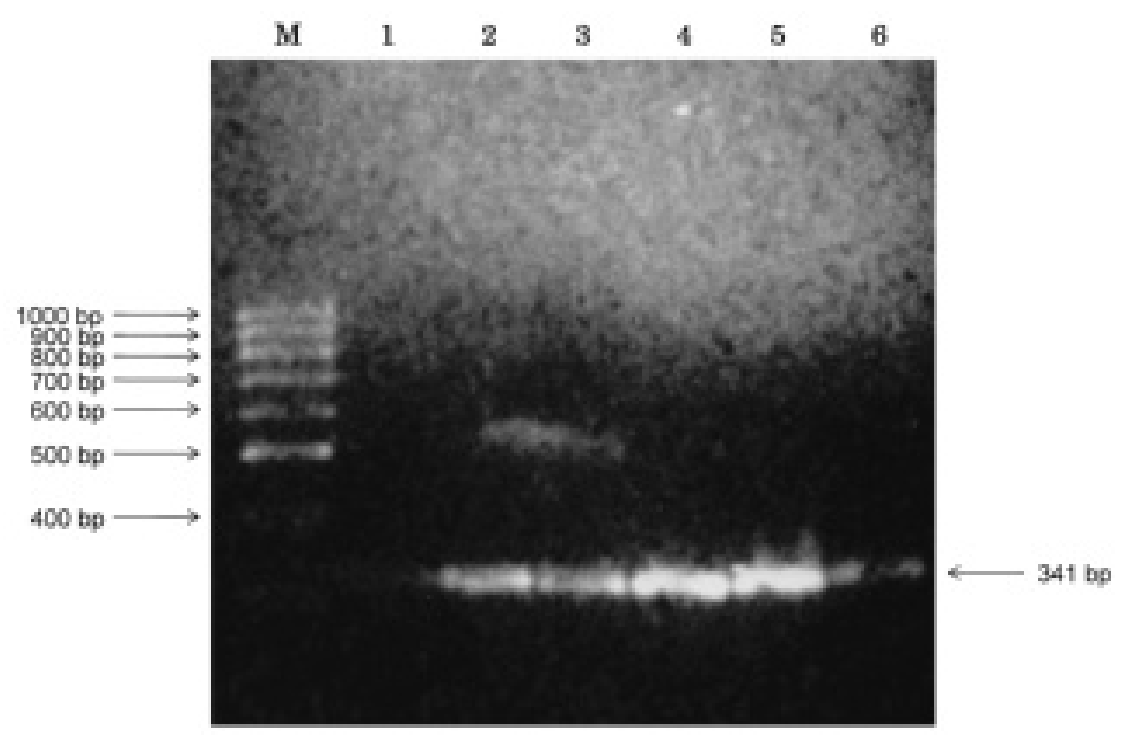

Figure 1A

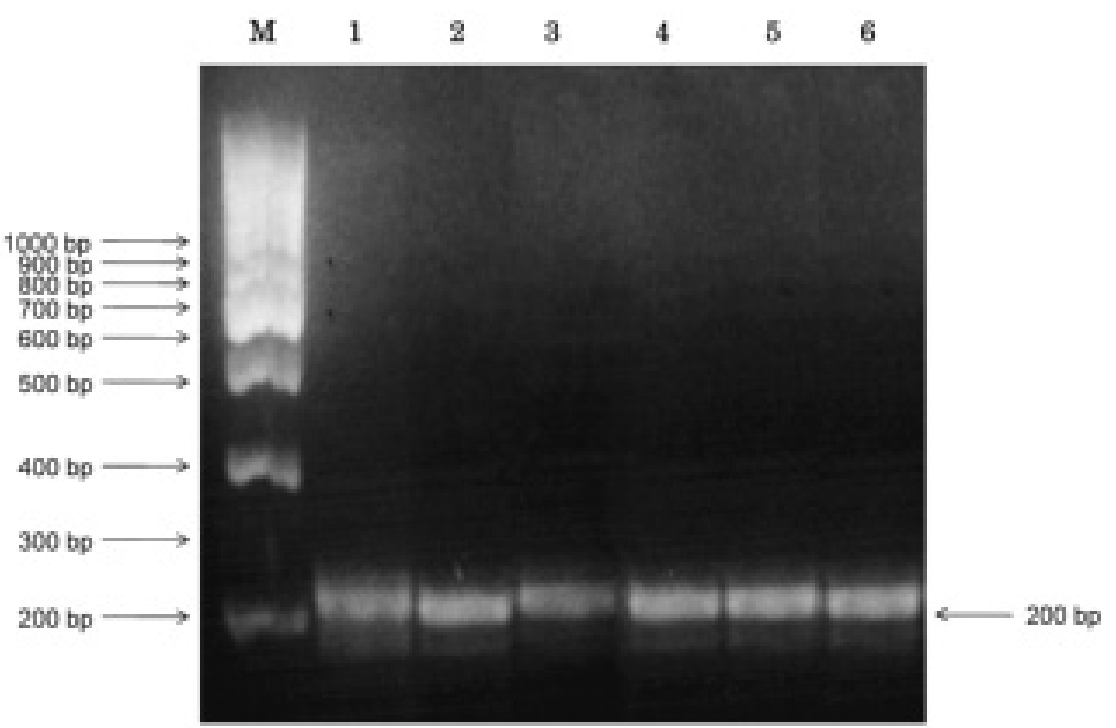

Figure 1B

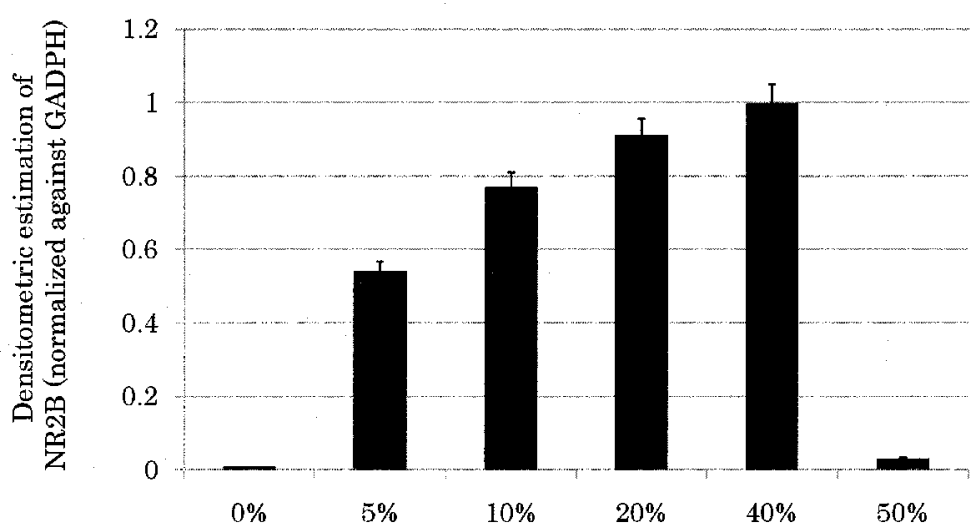

Rat groups with soybean-consumption (\% from total calorie)

Figure 1C

Fig. 1 RT-PCR results of the NR2B gene expression. PCR products identified following RT-PCR of NR2B gene expression. The presence of a 341 base pair (bp) fragment represents expression of NR2B (A). The presence of a $200 \mathrm{bp}$ fragment represents expression of the internal control, GAPDH (B). Densitometric estimation of NR2B normalized against GADPH (C). M : markers, line 1: control, lanes 2-6: groups treated with different concentrations of soybean : $5 \%, 10 \%, 20 \%, 40 \%$ and $50 \%$, respectively. 
Escape Latency from Morris Water Maze Test

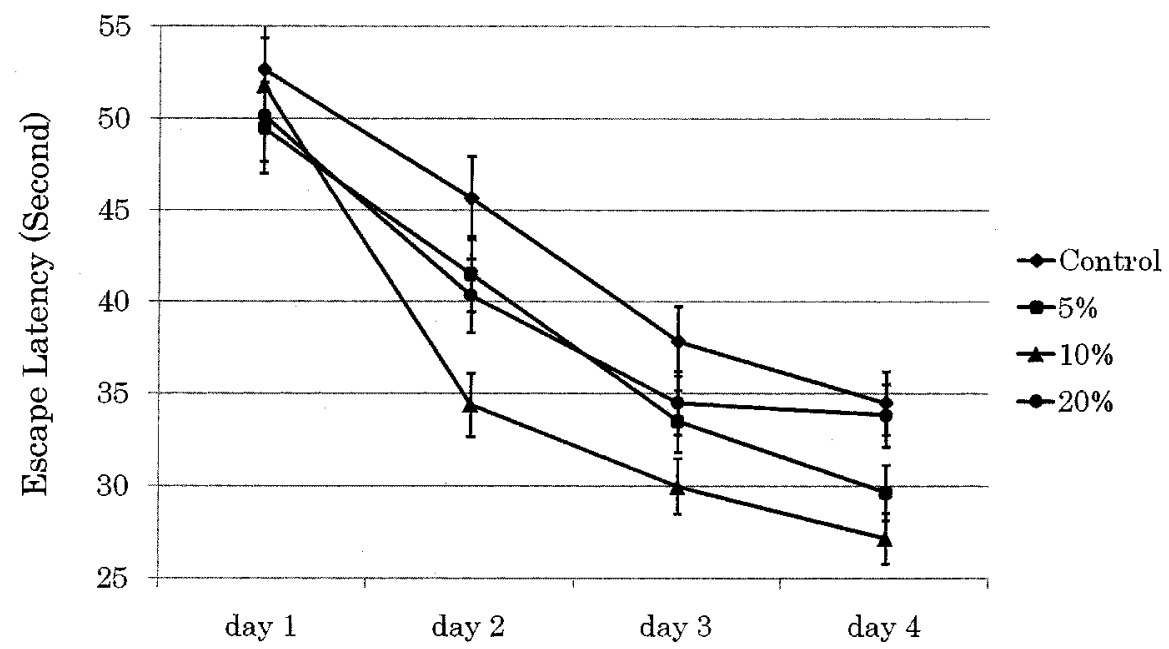

Fig. 2 Escape latency time (seconds) results from the Morris Water Maze Test for rats treated and untreated-with Glycine max extract diets.

\section{Discussion}

A growing body of evidence indicates that the isoflavone content of soybeans could inhibit cell growth and proliferation. This non-nutritious substance has a biphasic effect; in low concentrations, isoflavones stimulate cell proliferation, whereas in high concentrations, they inhibit cell proliferation. ${ }^{17}$ Based on these facts, an anti-tumorigenesis effect of soy isoflavones has been proposed. ${ }^{18}$ The NMDA receptor (NMDAR) mediates synaptic transmission and neural plasticity at many sites in the mammalian central nervous system (CNS) and also neuronal cell death. ${ }^{19,20}$ Actively blocking the NMDA receptor in vitro exacerbates ongoing neurodegeneration, whereas enhancing synaptic NMDA receptor activity is neuroprotective. ${ }^{21}$ Recently, the NR2B receptor has been shown to have different roles in supporting neuron survival and in mediating neuronal cell death, and, hence, has a beneficial impact on neurotoxicity of the brain. ${ }^{14}$ Several studies have shown that the effect of the soybean on growth and development is beneficial, and its consumption is widely recommended as a preventative measure against the development of

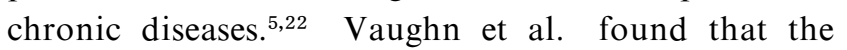
administration of hydrolyzed soy proteins in rat brains can cause modest, significant short-term decreases in bodyweight independently of food consumption. ${ }^{10}$ Even though we did not observe changes in bodyweight in this study, our results demonstrated that high concentrations of dietary soybean (Glycine max extract) can significantly increase the cerebrum weight, whereas it decreases the cerebellum weight.

Behavioral assays, often in combination with pharmacological or genetic manipulations, have demonstrated the role of the NR2B subunit in mediating feeding behavior and other related physiological functions, such as learning, memory, pain and synaptic plasticity. Mice over-expressing the NR2B subunits exhibit superior abilities in various tests of learning and memory (novel object recognition task, fear conditioning, fear extinction and water maze). In an NR2B knock-down model of aging rats, NR2B antisense treatment abolished long-term potentiation and impaired spatial learning, as measured by the Morris water maze test. ${ }^{23}$ Our results showed that rats treated with Glycine max extract diets can escape faster from water by swimming to a platform than control rats ( $5 \%, 10 \%$ and $20 \%$ diet groups were up to $14 \%$, $21.6 \%$, and $1.94 \%$ faster, respectively). In the $10 \%$ group, this difference was statistically significant $(\mathrm{p}=$ $0.01)$. In line with this finding, the NR2B gene expression was gradually increased in $5 \%, 10 \%$ and $20 \%$ groups $(0.55,0.78$, and 0.91 , respectively 1$)$ as shown in Figure 1C. Taken together, these results suggest that a 10\% Glycine max extract diet can increase the expression of NR2B, which plays an essential role in learning and spatial memory, as proven with MWMT.

Over the last several years, an increasing number of studies have demonstrated the importance of the NR2B subunit in determining the pharmacological and functional properties of the NMDA receptor. Evidence suggested that the NMDA receptors are critical for corticogenesis, neuronal migration, and synaptogenesis during brain development. Recently, Liu Y et al. reported that activation of NR2B-containing NMDA receptors results in excitatoxicity and increases neuronal apoptosis. ${ }^{14}$ mRNA for the NR2B 
subunit is significantly decreased in a majority of cerebral cortex regions and in dentate gyrus granule cells as mice become older. ${ }^{24}$ The change in NR2B transcript expression was observed in 5\%, 10\%, 20\%, and $40 \%$ soybean diet groups, but it returned to baseline in the $50 \%$ soybean diet group. Activation of the NR2B subunit was related to neurotoxicity and increased neuronal apoptosis, whereas low activation of the NR2B subunit was associated with cell survival. In line with our results, decreased NR2B gene expression might be related to the neurotoxic effect that leads to neuronal cell death in the high concentration (50\%) group after reaching a peak in the $40 \%$ group. However, the functional consequences of a gradual increase and then a sudden decrease in NR2B RNA expression in our study remain unclear. This event may lead to apoptosis of the brain cells, especially in the cerebellum, where loss of brain cells causes abnormalities in body movement. Based on this observation, we suspected the brain damage was located mostly in cerebellum cells. Further study will be needed to elucidate the mechanisms of the phenomena observed in this study.

\section{Conclusion}

In summary, the low concentration of Glycine max extract ( $<5 \%$ from total calorie) diet was recommended, and levels of soybean extract from $5 \%$ to $10 \%$ were well tolerated (for four weeks), improving cognitive vitality; however, more than $20 \%$ was not recommended. The highest concentrations of Glycine max extract $(40 \%$ and $50 \%)$ were found to have neurotoxic effects in vivo.

\section{Acknowledgements}

This work was supported by a grant-in-aid for scientific research from Universitas Padjadjaran, Bandung, Indonesia. We thank Prof. Muchtan Sujatno (Universitas Padjadjaran, Indonesia) Prof. Herri S Sastramihardja (Universitas Islam Bandung, Indonesia) and Leri Septiani Faried, M.D., Ph.D. (Gunma University, Japan) for fruitful discussion, and we thank Santun Bhekti (Universitas Padjadjaran, Indonesia) and Maya Tejasari (Universitas Islam Bandung, Indonesia) for technical assistance.

\section{References}

1. Lee HP, Gourley L, Duffy SW, et al. 1991. Dietary effects on breast-cancer risk in Singapore. Lancet, 337 : 1197.

2. Daniel. 2006. Lecithin benteng perlindungan sel dari kerusakan. Majalah Farmacia, 5 : 50.

3. Cahyadi W. Kedelai khasiat dan technology. $1^{\text {st }}$ edition; Yustianti F (ed). Jakarta, Bumi Aksara 2007.

4. Kreijkamp-Kaspers S, Kok L, Grobbee DE, et al. 2004. Effect of soy proteincontaining isoflavones on cognitive function, bone mineral density, and plasma lipids in post -menopausal women: A randomized controlled trial. JAMA, $292: 65-74$

5. van Kempen T.A, van Heugten E, Moeser A.J, et al. 2006. Selecting soybean meal characteristics preferred for swine nutrition. J Anim Sci 84: 1387.

6. Kwong WY, Miller DJ, Ursell E, et al. 2006. Imprinted gene expression in the rat embryo-fetal axis is altered in response to periconceptional maternal low protein diet. Reproduction, 132 : 265.

7. Cederroth CR, Vinciguerra M, Kuhne F, et al. 2007. A phytoestrogen-rich diet increases energy expenditure and decreases adiposity in mice. Environ Health Perspect 115 : 1467.

8. Bernbaum JC, Umbach DM, Ragan NB, et al. 2008. Pilot studies of estrogen- related physical findings in infants. Environ Health Perspec, 116 : 416.

9. Chavarro JE, Rich-Edwards JW, Rosner BA, Willett WC. 2006. Iron intake and risk of ovulatory infertility. Obstet Gynecol 108: 1145.

10. Vaughn N, Rizzo A, Doane D, et al. 2008. Intracerebroventricular administration of soy protein hydrolysates reduces body weight without affecting food intake in rats. Plant Foods Hum Nutr 63 : 41.

11. Bateman HL, Patisaul HB. 2008. Disrupted female reproductive physiology following neonatal exposure to phytoestrogens or estrogen specific ligands is associated with decreased GnRH activation and kisspeptin fiber density in the hypothalamus. Neurotoxicology 29: 988.

12. McBain CJ and Mayer ML. 1994. N-methyl-D-aspartic acid receptor structure and function. Physiol Rev 74: 723.

13. Choi DW and Rothman SM. 1990. The role of glutamate neurotoxicity in hypoxic-ischemic neuronal death. Annu Rev Neurosci 13 : 171.

14. Liu Y, Wong TP, Aarts M, Rooyakkers A, et al. 2007. NMDA receptor subunits have differential roles in mediating excitotoxic neuronal death both in vitro and in vivo. $J$ Neurosci 27: 2846.

15. Loftis JM and Janowsky A. 2003. The N-methyl-D-aspartate receptor subunit NR2B : localization, functional properties, regulation, and clinical implications. Pharmacol Ther 9: 55.

16. Morris R. 1984. Developments of a water-maze procedure for studying spatial learning in rat. $\mathrm{J}$ Neuroscince Methods, 11 : 47-60.

17. Chen AC and Donovan SM. 2004. Genistein at a concentration present in soy infant formula inhibits $\mathrm{Caco}^{-2 \mathrm{BBe}}$ cell proliferation by causing $\mathrm{G} 2 / \mathrm{M}$ cell cycle arrest. $J$ Nutr 134: 1303.

18. Xiao R, Badger TM, Simmen FA. 2005. Dietary exposure to soy or whey proteins alters colonic global gene expression profiles during rat colon tumorigenesis. Mol Cancer 4: 1 .

19. Mayer ML and Westbrook GL. 1987. Permeation and block of N-methyl-D-aspartic acid receptor channels by divalent cations in mouse cultured central neurones. $J$ Physiol 394: 501.

20. Meldrum B, Garthwaite J. 1990. Excitatory amino acid neurotoxicity and neurodegenerative disease. Trends Pharmacol Sci 11 : 379.

21. Papadia S, Stevenson P, Hardingham NR, Bading H, Hardingham GE. 2005. Nuclear $\mathrm{Ca}^{2+}$ and the cAMP response element-binding protein family mediate a late phase of activity-dependent neuroprotection. $J$ Neurosci 25: 4279 . 
22. Anderson GH, Moore SE. 2004. Dietary proteins in the regulation of food intake and body weight in humans. $J$ Nutr 134 : 974S

23. Clayton DA, Mesches MH, Alvarez E, Bickford PC, Browning MD. 2002. A hippocampal NR2B deficit can mimic age-related changes in long-term potentiation and spatial learning in the Fischer 344 rat. J Neurosci, 22 : 3628-3637.

24. Magnusson KR. 2000. Declines in mRNA expression of different subunits may account for differential effects of aging on agonist and antagonist binding to the NMDA receptor. J Neurosci 20: 1666. 